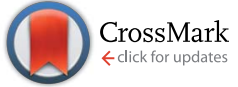

Cite this: RSC Adv., 2017, 7, 14790

Received 23rd November 2016 Accepted 1st March 2017

DOI: 10.1039/c6ra27217g

rsc.li/rsc-advances

\section{Electrodeposition of aluminium foils on carbon electrodes in low temperature ionic liquid $\dagger$}

\author{
Xianneng Tu, ${ }^{\text {ab }}$ Junling Zhang, ${ }^{\text {b }}$ Meng Zhang, ${ }^{\text {a }}$ Yingjun Cai, ${ }^{b}$ Haiyan Lang, ${ }^{\text {b }}$ \\ Guoxin Tian ${ }^{a}$ and Yanli Wang ${ }^{a}$
}

To inhibit dendrite formation for aluminium electrodeposition in room-temperature ionic liquid electrolyte, a promising method for electrodeposition of non-dendritic aluminium foils on carbon cathodes is investigated. The effect of current density, deposition time, temperature, and cathode materials on the deposit morphology of aluminium foils in $\mathrm{AlCl}_{3}-1$-butyl-3-methyl-imidazolium chloride $\left(\mathrm{AlCl}_{3}-[\mathrm{Bmim}] \mathrm{Cl}\right.$ ) ionic liquid electrolyte was also studied. The prepared aluminium foils are compact, bright and easy to peel off from the carbon electrodes after electrodeposition. The experimental results show that the high current density and low electrowinning temperature is responsible for the compactness of aluminium foils. The intensity of the (200) plane enhances with the increase of current density. Cathodic current efficiencies of the electrodeposition process are from $79 \%$ to $87 \%$. The mechanisms of electrodeposition of non-dendritic aluminium foils in ionic liquids are proposed.

\section{Introduction}

Aluminium is lightweight and has excellent corrosion resistance and electric conductivity and is thus a promising material for various applications. The conventional industrial aluminium electrowinning process such as the Hall-Heroult ${ }^{1}$ process uses a high temperature of $800{ }^{\circ} \mathrm{C}$ to $950{ }^{\circ} \mathrm{C}$, consumes high energy (15 to $18 \mathrm{~kW} \mathrm{~h} \mathrm{~kg}{ }^{-1}$ aluminum), and generates pollution gases such as $\mathrm{CO}, \mathrm{CO}_{2}, \mathrm{CF}_{4}$, fluorides, etc. ${ }^{2}$ Ionic liquids (ILs) are widely studied in aluminium electrolysis due to their unique chemical and physical properties. It has advantages of low energy consumption ( $9.1 \mathrm{~kW} \mathrm{~h} \mathrm{~kg}^{-1}$ aluminum), low operating temperatures $\left(\leq 100{ }^{\circ} \mathrm{C}\right)$, no emission of pollutants, and no gases are evolved during the electrolysis, as compared with the conventional industrial aluminum electrowinning processes. Electrodeposition of aluminium in low temperature ionic liquid process shows a good application prospect for aluminium electrowinning and electrofining. . $^{\mathbf{3} 4}$

Cathode materials have effect the interaction energy of the electrodeposited adatoms with substrate in the low temperature electrolysis process. ${ }^{5,6}$ Strong interaction energy of deposit adatoms is in favor of yielding aluminium in the case of

\footnotetext{
${ }^{a}$ Harbin Engineering University, Harbin 150001, P. R. China. E-mail: happymeng1980@hrbeu.edu.cn

${ }^{b}$ Beijing Key Laboratory of Ionic Liquids Clean Process, Key Laboratory of Green Process and Engineering, Institute of Process Engineering, Chinese Academy of Sciences, Beijing 100190, P. R. China

$\dagger$ Electronic supplementary information (ESI) available: Schematics of the electrolytic cell, mapping image of the cross-section, EDS analysis of electrodeposited aluminium foils and SEM image of aluminium foils. See DOI: $10.1039 /$ c6ra27217g
}

electroplating aluminium with excellent adhesion to the substrates. Most of the previous studies concerning the electrodeposition of aluminium mainly focused on aluminium electroplate on metal substrates from room-temperature ionic liquids, such as stainless steel, ${ }^{7}$ tungsten, ${ }^{8-10}$ copper, ${ }^{11-13}$ which could get compact and adherent deposits. The electrodeposition of aluminium on aluminium substrate mainly was studied in recycling and refining of aluminum. ${ }^{\mathbf{1 0 , 1 4 - 1 6}}$ But dendritic deposition, which was commonly observed in recycling and refining electrodeposition, hinders the production process. Phenomena of ramified electrochemical growth has been studied. ${ }^{17,18}$ The depletion of ions generates anisotropy surface kinetics and local electric fields near the cathode which readily leads to the dendrite at the edge of deposits. The dendritic arm causes short circuits between anodes and cathodes, which leads to production shutdown and reduces efficiency of the process. Hence, the dendritic aluminium electrodeposit is one of major problem concerning low temperature aluminium electrowinning process. Wiechmann et al. ${ }^{19}$ estimated that the elimination of short circuiting can improve earning up to $15 \%$ because of increasing current efficiency, current density, and production in the copper electrorefining process. Reddy and coworkers ${ }^{\mathbf{1 4 , 1 5}}$ reported electrowinning and electrorefining of aluminium used modified aluminium cathode to eliminate dendritic aluminium electrodeposit.

However, the electrodeposition of aluminium on non-metal substrates (such as glassy carbon or graphite) in ionic liquid are seldom reported. Osteryoung ${ }^{20}$ reported the electrochemical behavior of aluminium on GC electrode in $\mathrm{AlCl}_{3}$-ionic liquids, but did not obtain the product and the morphology of aluminium particles. 
To the best of our knowledge, the electrodeposition of aluminium foils on the metal or nonmetal substrates in a low temperature $\mathrm{AlCl}_{3}-[\mathrm{Bmim}] \mathrm{Cl}$ bath has not previously been explored. Herein, we developed a novel method that makes aluminium foils large, compact and easily peel off from substrate. The electrodeposition of aluminium foils from $\mathrm{AlCl}_{3}-$ [Bmim]Cl with a molar ratio of $2: 1$ on the carbon cathode was investigated. And the mechanisms of electrodeposition of nondendritic aluminium foils are also proposed.

\section{Experimental}

\subsection{Materials and chemicals}

[Bmim]Cl was purchased from LinZhuo Tech. En. Co., anhydrous $\mathrm{AlCl}_{3}$ was purchased from Sinopharm Chemical Reagent Co. $\left(\mathrm{AlCl}_{3},>99 \%\right)$ was used without further purification. All the chemicals used in this work were purchased commercially with analytic grade and used as received.

\subsection{Preparation and characterization of $[\mathrm{Bmim}] \mathrm{Cl}-\mathrm{AlCl}_{3}$}

$[\mathrm{Bmim}] \mathrm{Cl}$ was dried for $48 \mathrm{~h}$ under vacuum at $100{ }^{\circ} \mathrm{C}$ to remove water. The final product was obtained as a white wax-like solid at room temperature. $\mathrm{AlCl}_{3}$ crystals were mixed with $[\mathrm{Bmim}] \mathrm{Cl}$ in a molar ratio of $2: 1$ yielding a dark yellow liquid, and then were pre-electrolyzed by aluminium plates as electrodes for $48 \mathrm{~h}$ to remove residual water and foreign material ion yielding a colorless liquid. And experiments were carried out in an argon-filled glove box (MIKROUNA Universal, $\mathrm{O}_{2}$ below $1 \mathrm{ppm}$, $\mathrm{H}_{2} \mathrm{O}$ below $\left.1 \mathrm{ppm}\right)$. The temperature of the sample was maintained to $\pm 0.1 \mathrm{~K}$ via a builtin precise Peltier thermostat.

\subsection{Electrodeposition of aluminium foils}

The experiments were carried out with a three-electrode system (Fig. S1a $\dagger$ ). The working electrodes were glassy carbon (GC, Aida, $3 \mathrm{~mm}$ diameter) or graphite (Aida, $10 \mathrm{~mm}$ diameter), the counter electrode was glassy carbon $(20 \mathrm{~mm} \times 20 \mathrm{~mm} \times 1 \mathrm{~mm})$, pure aluminium wire ( $1 \mathrm{~mm}$ diameter, 99.9\% pure, Alfa Aesar) coated by a heat shrink tube was used as reference electrode. The electrodes were first polished to a nearly mirror finish with an aqueous slurry of $0.05 \mu \mathrm{m}$ alumina. Thereafter, they were rinsed with ultrapure water and ultrasonically cleaned in ethanol for $5 \mathrm{~min}$ and finally dried with cold $\mathrm{N}_{2}$ flow.

Experiments were performed with an electrochemical workstation (AutoLab) controlled by Nova 1.2 software in a threeelectrode cell. The electrolyte was stirred at a constant speed using a magnetic stirrer. The temperature was controlled by a digital hot plate (IKA, C-MAG, HS-7), and a thermometer was inserted into the electrolyte to monitor the temperature. After the electrolysis, deposit was carefully cleaned several times with $\mathrm{CH}_{2} \mathrm{Cl}_{2}$ and drying and weighting before observed.

\subsection{Material characterizations}

Bulk powder X-ray diffractograms were collected with Empyrean, PANalytical B. V. equipped with a $\mathrm{Cu} \mathrm{K} \alpha$ source $(\lambda=1.5406$ A). Scanning electron micrographs were taken at $5 \mathrm{kV}$ with a Hitachi SU8020 SEM equipped with an SE/BSE detector. Energy dispersive spectra (EDS) were taken at $20 \mathrm{kV}$.

\section{Results and discussion}

\subsection{Effect of current density on deposition layer}

To evaluate the morphology of aluminium deposits under different current density on GC electrode, chronopotentiometry study is adopted. Fig. 1 shows the surface morphology of the aluminium deposits under different current density. Under the same applied electric charge, the deposited particles become coarser at low current density $\left(16 \mathrm{~mA} \mathrm{~cm}{ }^{-2}\right)$. Meanwhile, deposited particles grow together and agglomerate rather than separated particles. However, with further increase of current density, the grain size of the deposits decreases.

At the low current density, the discharge of ions at the cathode is low, so the growth rate of nuclei will be higher than the rate of new nuclei formation; as a result, the deposits become coarse. ${ }^{21}$ However, as current density increased, the deposited particles become fine-grained, ${ }^{22}$ which can be attributed to the faster formation rate of new nucleus as compared with the growth rate of that. It is also observed that the high current density ( 32 and $57 \mathrm{~mA} \mathrm{~cm}^{-2}$ ) leads to a uniform deposition, and the surface becomes relatively smooth. Ionic liquids decompose when the potential larger than their equilibrium potential at $57 \mathrm{~mA} \mathrm{~cm} \mathrm{~cm}^{-2}$ are applied.

Fig. 2 shows the variation of potential with time at different current density on GC electrode at $50{ }^{\circ} \mathrm{C}$. It is clear that the cathodic potential becomes negative with an increase of current density. An increase in current density can result in a higher overpotential which causes a rising nucleation rate. During electrodeposition the higher rate of nucleation is, the finer grain of the deposits is. ${ }^{23}$ It is evident that the grain size of the deposits decreases with increasing current density from 16 to 57 $\mathrm{mA} \mathrm{cm}{ }^{-2}$, which is consistent with our SEM image (Fig. 1) and the previous report. ${ }^{24}$ There are overpotential electrodeposition
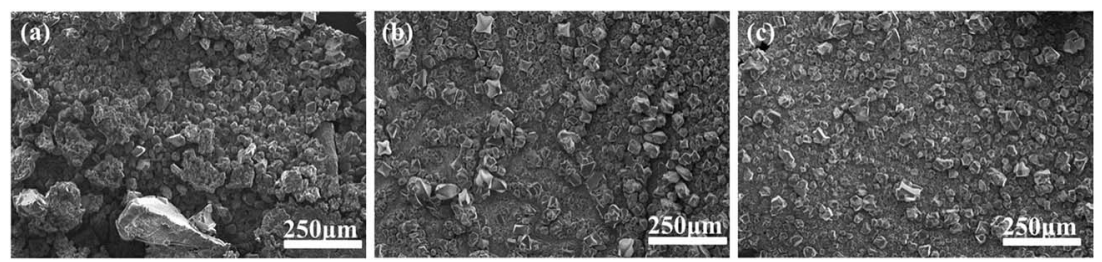

Fig. 1 SEM images of aluminium foil under different current density and same applied electric charge deposition (a) $16 \mathrm{~mA} \mathrm{~cm}{ }^{-2}, 2 \mathrm{~h} \mathrm{(b)} 32 \mathrm{~mA}$ $\mathrm{cm}^{-2}, 1 \mathrm{~h}$ (c) $57 \mathrm{~mA} \mathrm{~cm}^{-2}, 0.55 \mathrm{~h}$ (temperature $=50^{\circ} \mathrm{C}$ ). 


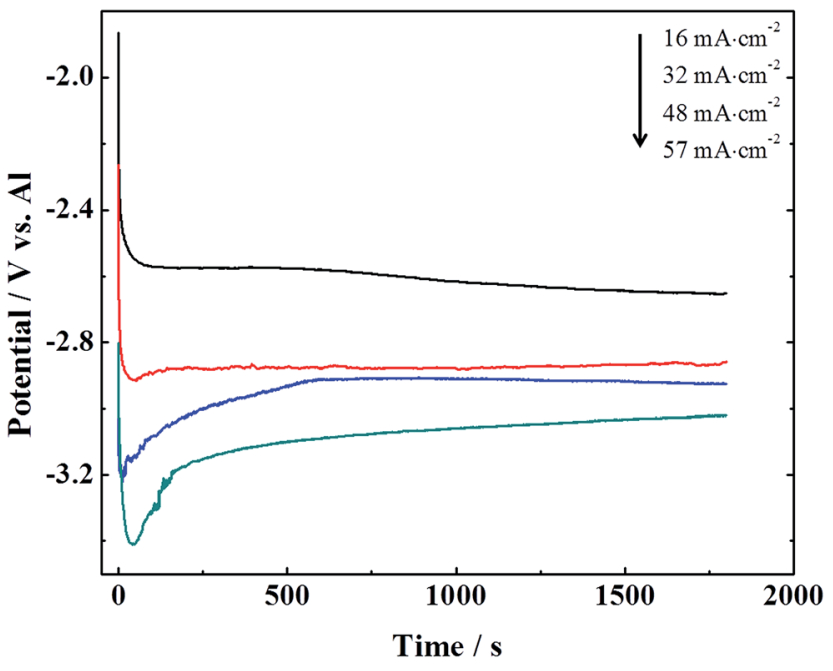

Fig. 2 Variation of potential with time at different current density on $\mathrm{GC}$ electrodes $50^{\circ} \mathrm{C}$.

on glassy carbon at various current densities, indicating a weak interaction energy of aluminium atoms with the GC substrate. ${ }^{5}$ It is easy to peel off aluminium foils from GC substrate after electrodeposition due to this weak interaction energy. The photography of aluminium foils on GC electrode after deposition is shown in Fig. S1c. $\dagger$

Fig. 3 shows the images of aluminium foils at different time intervals with a current density $57 \mathrm{~mA} \mathrm{~cm}^{-2}, 50{ }^{\circ} \mathrm{C}$ (all deposits are compact). Fig. $3 \mathrm{a}$ and $\mathrm{b}$ show the SEM images of aluminium foils which are deposited for $0.5 \mathrm{~h}$ and $1 \mathrm{~h}$, respectively. It can clearly be seen that the surfaces of aluminium foils are compact and homogeneous, and aluminium particles are granular and isolated. With increasing the time interval (Fig. 3c and d) the aluminium foils become clustering and dendritic. The SEM results show that $1 \mathrm{~h}$ can be the transition deposit time interval which result in the morphology changes from granular to agglomeration at current density of $57 \mathrm{~mA} \mathrm{~cm}^{-2}$.
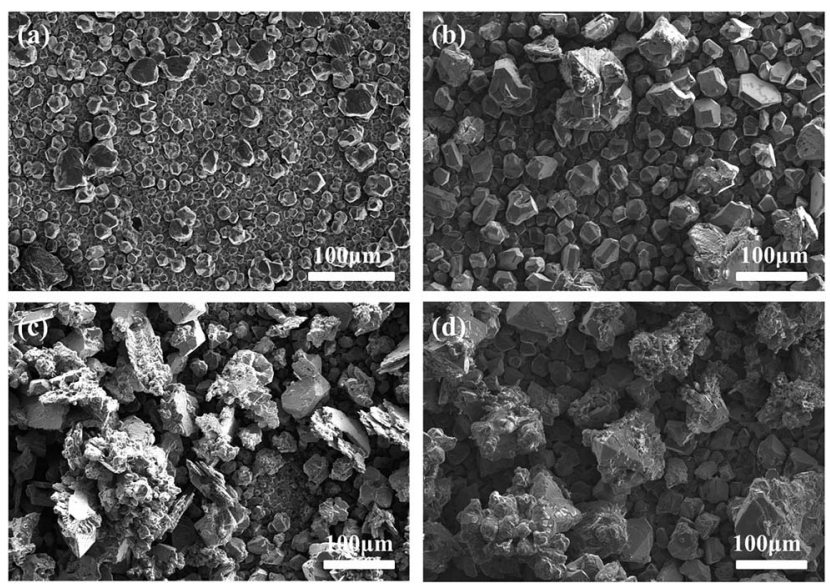

Fig. 3 SEM images of the aluminium foils at different time intervals (a) $0.5 \mathrm{~h} \mathrm{(b)} 1 \mathrm{~h} \mathrm{(c)} 2 \mathrm{~h}$ (d) $4 \mathrm{~h}$ (current density $=57 \mathrm{~mA} \mathrm{~cm}^{-2}$, temperature $=50^{\circ} \mathrm{C}$ ).
The XRD patterns of electrodeposits at varies current density with same applied electric charge are shown in Fig. 4a. The XRD patterns of all the samples match well with the standard values for aluminium in JCPDS cards no. 01-089-2769. It shows only the diffraction peaks of aluminium. The EDS results also confirm that the deposit is only composed of aluminium in Fig. S2.†

The normalized integrated intensity, $P_{h k l}$, for the (111), (200), (220), (311), and (222) reflections were calculated by literatures. ${ }^{13,25,26}$ The calculated crystallographic orientations of electrodeposits obtain with different current densities are plotted in Fig. 4b. It is obviously observed from the crystallographic orientation that the intensity of the (200) plane increase and the intensity of the (111) plane decrease with increasing current density. These results show that current density has significant influence on the crystallographic orientation.

Fig. 5 shows the variation of current efficiency as a function of applied current density at temperature $50{ }^{\circ} \mathrm{C}$. The results show that the current efficiency is from $79.1 \%$ to $89.5 \%$ as the current density increases from 16 to $57 \mathrm{~mA} \mathrm{~cm}{ }^{-2}$. The aluminium foils have weight loss in the cleaning process. The more dendrites of aluminum foils have, the larger of aluminium foils' weight lose. The clustering and dendritic aluminium foils have a pretty large weight loss in the cleaning process at low current density. So, the current efficiency is indirectly responsible for the compact degrees of aluminium foils. The aluminium foils become compact with the increase of current density.

\subsection{Effect of temperature on deposition layer}

The deposit morphologies at different temperatures are shown in SEM images (Fig. 6). As shown in Fig. 6, the shapes of particles are uniform at $40{ }^{\circ} \mathrm{C}$ and $50{ }^{\circ} \mathrm{C}$ and at $60{ }^{\circ} \mathrm{C}$ is irregular. However, a powdery bulk aggregation is found at $70^{\circ} \mathrm{C}$, which formed non-compact foil on GC cathode surface (no pictures). At the low temperature, the aluminium foils seem to be smooth, compact and uniform. The thermal motion of deposit molecules is drastic with increased temperature, the arrangement of deposit molecules becomes disorder at high temperature. Hence, the particle sizes of aluminium deposit increase and the particle shapes of aluminium become more irregular with increasing of temperature.

Fig. 7 shows the variation of current efficiencies and thickness of aluminium foils at different temperature with $32 \mathrm{~mA}$ $\mathrm{cm}^{-2}$ and deposit time of $1 \mathrm{~h}$. The deposit thickness increases when temperature increases. Because the particles are irregular and the grain sizes increase at high temperature. The decrease in current efficiency at high temperatures may be due to two reasons. First, when the temperature of the electrolytes increases, the rate of oxidized species $\left(\mathrm{Cl}^{-}\right)$dispersing and formed $\mathrm{Cl}_{2}$ dissolving in the electrolytes at the anode also increases. Then they could be transported to the cathode where they reoxidize deposits by forming chlorides, and dissolves in the electrolytes. Second, the stability of [Bmim]Cl deteriorate with increased temperature. It is easily happened that the 

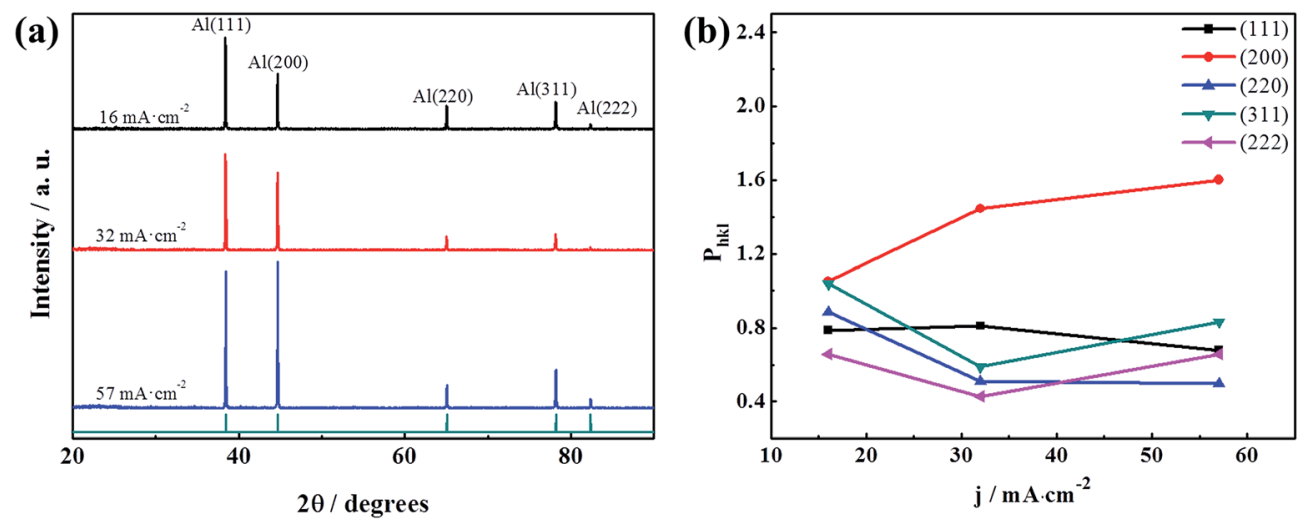

Fig. 4 (a) XRD pattern of aluminium foils at different current density with same applied electric charge $\left(16 \mathrm{~mA} \mathrm{~cm}{ }^{-2}, 2 \mathrm{~h} ; 32 \mathrm{~mA} \mathrm{~cm}{ }^{-2}, 1 \mathrm{~h} ; 57 \mathrm{~mA}\right.$ $\mathrm{cm}^{-2}, 0.55 \mathrm{~h}$ ). (b) Normalized peak intensity, $P_{h k l}$, from XRD reflections of the samples obtained in $\mathrm{AlCl}_{3}-[\mathrm{Bmim}] \mathrm{Cl}$ as a function of current density (temperature $=50^{\circ} \mathrm{C}$ ).

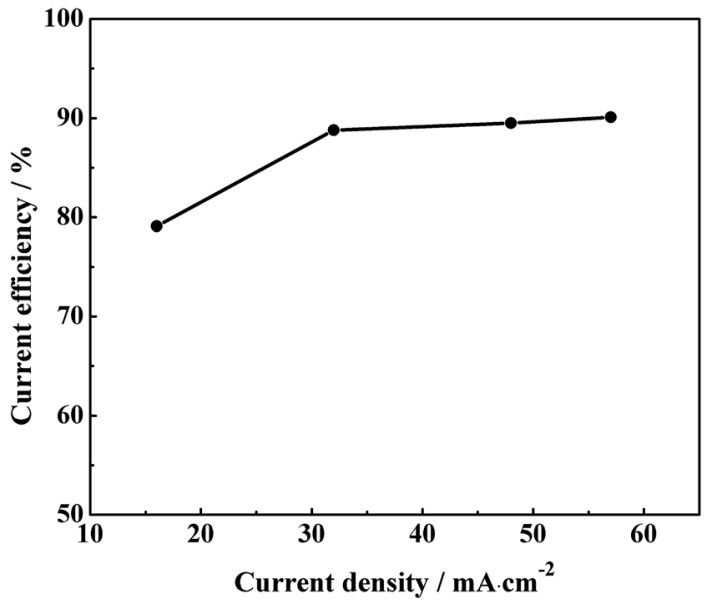

Fig. 5 The current efficiency of different current density (temperature $=50^{\circ} \mathrm{C}$ ).

$[\mathrm{Bmim}]^{+}$cation was unstable to reduction on cathode at high temperature. ${ }^{27,28}$

\subsection{Nucleation behavior of aluminium on GC cathode}

Fig. 8a shows the chronoamperometric current-time transients for $\mathrm{AlCl}_{3}-[\mathrm{Bmim}] \mathrm{Cl}$ using potential between $-0.6 \mathrm{~V}$ and $-0.8 \mathrm{~V}$ at $50{ }^{\circ} \mathrm{C}$. There are initial rises in current density which peaks at a particular current density depending on the applied overvoltage and then decays. With time the current density decays due to a diffusion limited steady state process. The initial electrodeposition of aluminium are diffusion limited steady state process on $\mathrm{GC}$ electrode in $\mathrm{AlCl}_{3}-[\mathrm{Bmim}] \mathrm{Cl}$ ionic liquid electrolytes. The initial stages of electrodeposition are usually associated with a three-dimensional nucleation growth. For a metal deposition process, a three-dimensional nucleation growth model is usually adopted. ${ }^{29}$ Furthermore, the nucleation mechanisms are of two different types, namely, instantaneous

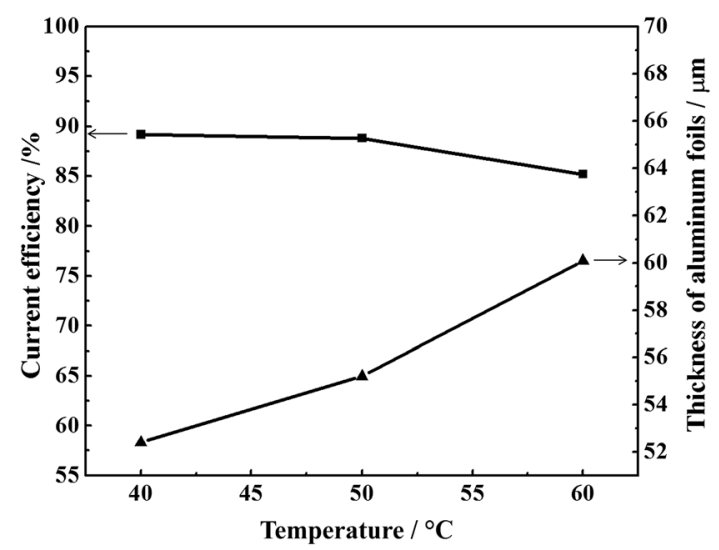

Fig. 7 The current efficiency and thickness of aluminium foil at different temperature (current density $=32 \mathrm{~mA} \mathrm{~cm}^{-2}$, deposit time $=$ $1 \mathrm{~h})$.
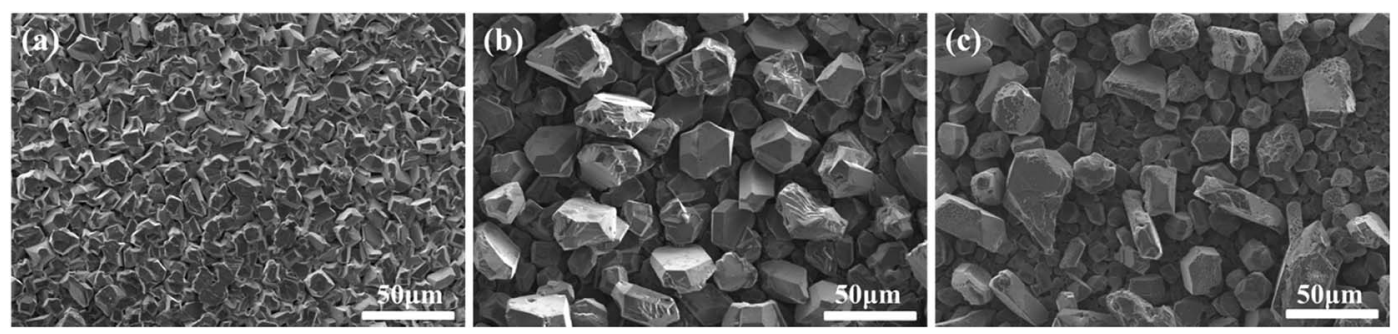

Fig. $6 \mathrm{SEM}$ images of aluminium foils at different temperature (a) $40^{\circ} \mathrm{C}$ (b) $50^{\circ} \mathrm{C}$ (c) $60^{\circ} \mathrm{C}$ (current density $=32 \mathrm{~mA} \mathrm{~cm}{ }^{-2}$, deposition time $=1 \mathrm{~h}$ ). 

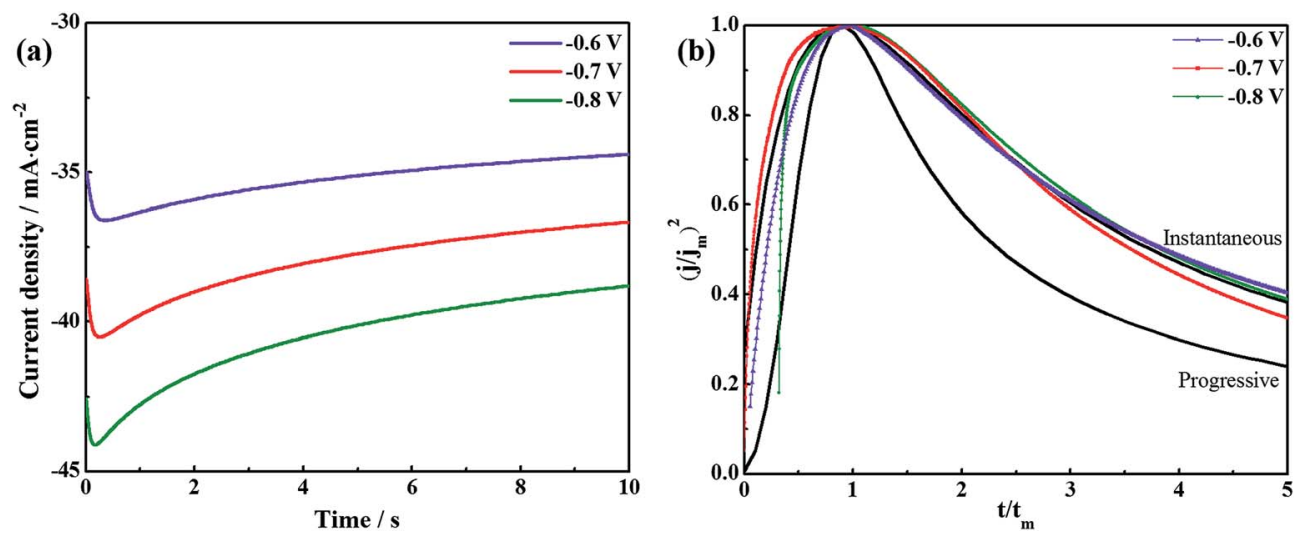

Fig. 8 (a) Chronoamperometric curves for GC electrode at various potentials. (b) Comparison of dimensionless $\left(j / j_{\mathrm{m}}\right)^{2} \mathrm{vs}$. $\left(t / t_{\mathrm{m}}\right)$ plots of nucleation/growth process on a glassy carbon electrode at various potentials (temperature $=50^{\circ} \mathrm{C}$ ) .

and progressive. ${ }^{30}$ The dimensionless current-time relations applicable for diffusion controlled three-dimensional instantaneous and progressive nucleation are given by eqn (1) and (2), respectively.

$$
\begin{aligned}
& \left(\frac{j}{j_{\mathrm{m}}}\right)^{2}=1.9542\left(t / t_{\mathrm{m}}\right)^{-1}\left\{1-\exp \left[-1.2564\left(t / t_{\mathrm{m}}\right)\right]\right\}^{2} \\
& \left(\frac{j}{j_{\mathrm{m}}}\right)^{2}=1.2254\left(t / t_{\mathrm{m}}\right)^{-1}\left\{1-\exp \left[-2.3367\left(t / t_{\mathrm{m}}\right)^{2}\right]\right\}^{2}
\end{aligned}
$$

where, $j$ is the current density $\left(\mathrm{mA} \mathrm{cm} \mathrm{cm}^{-2}\right)$ at any time $t, i_{\mathrm{m}}$ is the maximum current density $\left.(\mathrm{mA} \mathrm{cm})^{-2}\right)$ at $t_{\mathrm{m}}$ time (s) where it occurs. The dimensionless current-time transients at different overpotential from the curves in Fig. 8a with theoretical nucleation processes are compared in Fig. 8b. The nucleation plots have good correlation with the theoretical curve for progressive nucleation at different applied potential. The aluminium electrodeposition from $\mathrm{AlCl}_{3}-[\mathrm{Bmim}] \mathrm{Cl}$ electrolytes precede via instantaneous nucleation process on GC electrode. Yue ${ }^{25}$ and Pradhan $^{31}$ also observed similar instantaneous nucleation with diffusion-controlled growth for the electrodeposition of aluminium from $\mathrm{AlCl}_{3}-[\mathrm{Bmim}] \mathrm{Cl}$ low temperature molten salt.

\subsection{Growth mechanism of electrodeposited aluminium foils}

The mechanism for electrodeposited aluminium foils on GC electrode from ILs is complicate and still unknown so far. We just can propose some possible process by referring to the experimental results. As illustrated in Fig. 9, the formation of aluminium foils on GC electrode is divided into 3 stages. At first, a thin compact layer of aluminum is first deposited on the cathode: the oxidized precursor $\left(\mathrm{Al}_{2} \mathrm{Cl}_{7}^{-}\right)$is electro-reduced to the fully reduced state (Al) and $\mathrm{AlCl}_{4}{ }^{-}$ions at the surface of electrode and produce thin non-dendrite aluminium compact layer by layer-by-layer growth; secondly, dendrites attach to thin compact layer: the dislocation of deposit particles makes aluminium dendrites (as 3D islands formation) and attaches on predeposited 2D aluminium compact layer. The thickness of dendrite-free compact layer depends on the aluminium particles sizes. The fine-grained particles lead to a relatively low deformation and high the density of aluminium particles at
Low current density
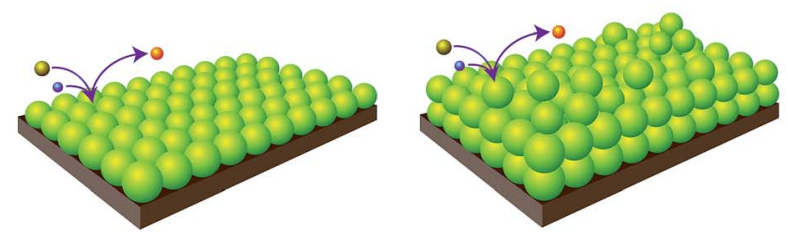

Deposited particle

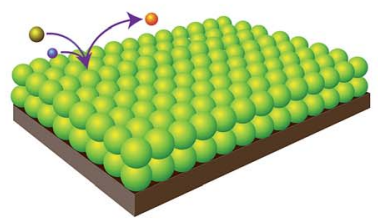

(1)

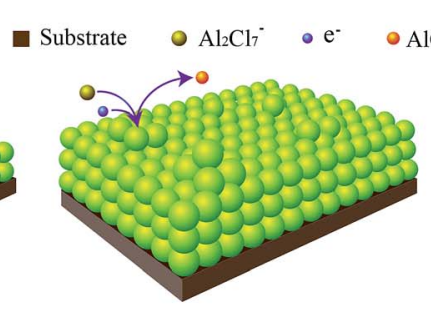

(2)

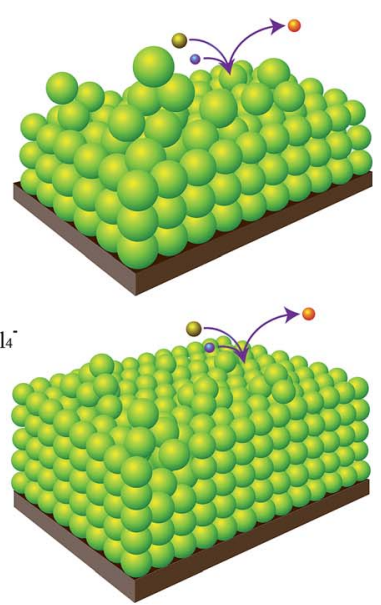

(3)

Fig. 9 Schematic illustration of aluminium foils on GC substrate by electrodeposition. 
high current density. Inversely, the coarse-grained particles result in a relatively high deformation, which are more likely to foils produce dendrite and form loose at low current density. The thickness of foils when the dendrites start occurring are thicker at high current density than the foils at low current density; lastly, the aluminium dendrites continue to grow. Simultaneously, the growth particles are filling up interstice between the dendrites to increase the thickness of compact layer. So, the fine-grained particles are prone to form compact layer.

It is significant to find out the thickness value of foils to start occurring dendrite at different current density. The thickness of aluminium foils on GC substrate is evaluated by EDS elemental (Al) mapping image of the cross-section (Fig. S3†). Table 1 shows the thickness of aluminium foils at different current density and deposition time. At current density $57 \mathrm{~mA} \mathrm{~cm}^{-2}$ and time interval 0.55 and $1 \mathrm{~h}$, the thickness of compact layer is equal to the total thickness. At time interval $2 \mathrm{~h}$, the thickness of compact layer is $184.3 \mu \mathrm{m}$. But the total thickness including dendrites is $188.5 \mu \mathrm{m}$. It means that compact foil begins to form dendrites (the total thickness is more than the thickness of compact layer). As deposition time delays to $4 \mathrm{~h}$, the compact layer and total thickness increase to 240.2 and $310.8 \mu \mathrm{m}$, respectively. The deposition thickness rises when current density and deposit interval time increase. Furthermore, the foils are easy to powder and rupture when the thickness of compact layer is smaller or dendrite is longer at low current density, which marks "a" in the Table 1 . These results verify our conjecture as Fig. 9.

\subsection{Deposition of large aluminium foils on graphite cathode}

In order to explore deposition of aluminium foils on other facile carbon substrates for industrial application, amplification experiments of large area aluminium foils have done. Fig. 10

Table 1 Thickness of aluminium foils at different current density and deposition time on GC electrode

\begin{tabular}{llll}
\hline $\begin{array}{l}\text { Current density } \\
\left(\mathrm{mA} \mathrm{cm}^{-2}\right)\end{array}$ & $\begin{array}{l}\text { Deposition } \\
\text { time }(\mathrm{h})\end{array}$ & $\begin{array}{l}\text { Thickness of } \\
\text { compact layer }(\mu \mathrm{m})\end{array}$ & $\begin{array}{l}\text { Total } \\
\text { thickness }^{b}(\mu \mathrm{m})\end{array}$ \\
\hline 57 & 0.55 & 55.3 & 55.3 \\
& 1 & 101.6 & 101.6 \\
& 2 & 184.3 & 188.5 \\
48 & 4 & 240.2 & 310.8 \\
& 0.5 & 46.0 & 46.0 \\
& 1 & 71.0 & 71.0 \\
32 & 2 & 118.0 & 118.0 \\
& 4 & 161.0 & 217.2 \\
& 0.5 & 30.0 & 30.0 \\
& 1 & 54.1 & 55.2 \\
& 2 & 70.0 & 120.0 \\
& $4^{a}$ & - & - \\
& $0.5^{a}$ & - & 41.0 \\
& 1 & 23.5 & 60.0
\end{tabular}

${ }^{a}$ Aluminium foils were not produced at the condition. ${ }^{b}$ Total thickness: the thickness of the aluminium foils including the dendrite.

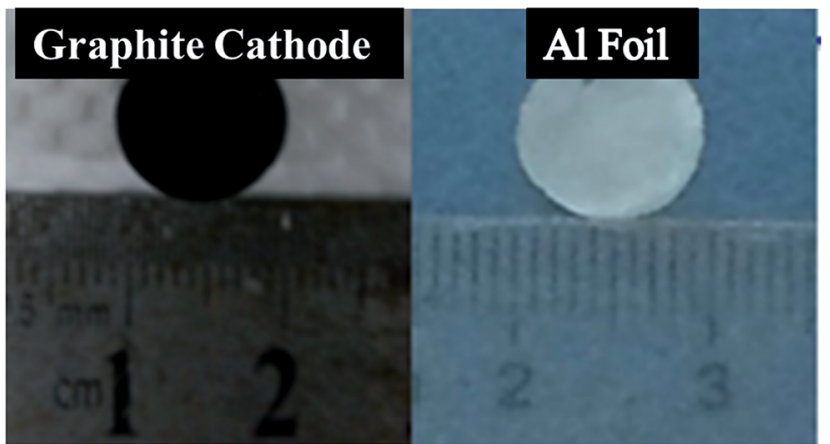

Fig. 10 The photograph of graphite cathode and aluminium deposit on graphite cathode (current density $=25 \mathrm{~mA} \mathrm{~cm}^{-2}$, temperature $=$ $\left.50{ }^{\circ} \mathrm{C}\right)$.

shows that the photograph of smooth graphite cathode (before experiment) and peeled aluminium foil from graphite cathode (after experiment). The deposited aluminium foil was compact and easily peeled from electrode at graphite cathode $(10 \mathrm{~mm}$ diameter). As shown in Fig. S4† (the SEM image of the large foil), the aluminium foil is non-dendritic and dense. We can completely obtain compact and uniform aluminium foils before the dendrite occurs.

\section{Conclusion}

The aluminium foils were prepared by low-temperature electrodeposition on carbon substrate using ionic liquid electrolyte $\left(\mathrm{AlCl}_{3}-[\mathrm{Bmim}] \mathrm{Cl}\right)$. Aluminium foils are dense, uniform and nondendritic by high current density and low deposition time. The current efficiency was dependent on different current density varying from $79 \%$ to $87 \%$. All of the electrodeposits exhibited a stronger intensity of (200) plane with increasing current density. The nucleation of aluminium on GC electrode is a 3-D instantaneous process at $50{ }^{\circ} \mathrm{C}$. Growth mechanism of aluminium foils was tentatively proposed including first formation of compact layer and dendrite, and following growth of compact layer and dendrite on GC electrode. More significantly, it offers an appealing avenue for dense, uniform, nondendritic and easily peeled off fabricating process of lowtemperature aluminium foils.

\section{Acknowledgements}

This work was financially supported by the National Natural Science Foundation of China (51104050, 51301050, 51202047, 51404230), the National Key Projects for Fundamental Research and Development of China (2016YFB01003032), the International Cooperation and Exchange of the National Natural Science Foundation of China (51561145020), the Scientific Research Foundation for Heilongjiang Postdoctoral (2016LBHZ10208), the Natural Science Foundation of Heilongjiang Province of China (E201413), the Technology Foundation for Selected Overseas Chinese Scholar of Heilongjiang Province (No. 159150130002), the Fundamental Research Funds for the Central Universities (HEUCF161501). 


\section{References}

1 M. Kondo, H. Maeda and M. Mizuguchi, JOM, 1990, 42, 3637.

2 M. M. Zhang, V. Kamavaram and R. G. Reddy, JOM, 2003, 55, A54-A57.

3 B. Wu, R. G. Reddy and R. D. Rogers, Essential Readings in Light Metals, 2001, vol. 2, pp. 1100-1107.

4 A. P. Abbott, G. Frisch, J. Hartley and K. S. Ryder, Green Chem., 2011, 13, 471-481.

5 W. J. Lorenz and G. Staikov, Surf. Sci., 1995, 335, 32-43.

6 L. Aldous, D. S. Silvester, C. Villagrán, W. R. Pitner, R. G. Compton, M. Cristina Lagunas and C. Hardacre, New J. Chem., 2006, 30, 1576-1583.

7 Q. X. Liu, E. Abedin, S. Zein and F. Endres, Surf. Coat. Technol., 2006, 201, 1352-1356.

8 R. T. Carlin, W. Crawford and M. Bersch, J. Electrochem. Soc., 1992, 139, 2720-2727.

9 P. K. Lai and M. Skyllas Kazacos, J. Electroanal. Chem. Interfacial Electrochem., 1988, 248, 431-440.

10 T. Jiang, M. J. Chollier Brym, G. Dubé, A. Lasia and G. M. Brisard, Surf. Coat. Technol., 2006, 201, 10-18.

11 Y. Zheng, S. J. Zhang, X. M. Lu, Q. Wang, Y. Zuo and L. Liu, Chin. J. Chem. Eng., 2012, 20, 130-139.

12 M. Zhang, V. Kamavaram and R. G. Reddy, Light Metals, 2005, vol. 2, pp. 583-588.

13 Q. Liao, W. R. Pitner, G. Stewart, C. L. Hussey and G. R. Stafford, J. Electrochem. Soc., 1997, 144, 936-943.

14 D. Pradhan and R. G. Reddy, Metall. Mater. Trans. B, 2012, 43, 519-531.

15 D. Pradhan, D. Mantha and R. G. Reddy, Electrochim. Acta, 2009, 54, 6661-6667.
16 A. P. Abbott, C. A. Eardley, N. R. S. Farley, G. A. Griffith and A. Pratt, J. Appl. Electrochem., 2001, 31, 1345-1350.

17 V. Fleury, J. H. Kaufman and D. B. Hibbert, Nature, 1994, 367, 435-438.

18 E. B. Jacob and P. Garik, Nature, 1990, 343, 523-530.

19 E. P. Wiechmann, G. A. Vidal and A. J. Pagliero, IEEE Trans. Ind. Appl., 2006, 42, 851-855.

20 J. Robinson and R. A. Osteryoung, J. Electrochem. Soc., 1980, 127, 122-128.

21 V. Kamavaram, D. Mantha and R. G. Reddy, J. Min. Metall., Sect. B, 2003, 39, 43-58.

22 C. C. Yang, Mater. Chem. Phys., 1994, 37, 355-361.

23 A. M. Rashidi and A. Amadeh, Surf. Coat. Technol., 2008, 202, 3772-3776.

24 Q. Zhang, Q. Wang, S. Zhang and X. Lu, J. Solid State Electrochem., 2013, 18, 257-267.

25 G. Yue, S. Zhang, Y. Zhu, X. Lu, S. Li and Z. Li, AIChE J., 2009, 55, 783-796.

26 T. Tsuda, T. Nohira and Y. Ito, Electrochim. Acta, 2002, 47, 2817-2822.

27 M. C. Kroon, W. Buijs, C. J. Peters and G. J. Witkamp, Green Chem., 2006, 8, 241-245.

28 M. C. Buzzeo, R. G. Evans and R. G. Compton, ChemPhysChem, 2004, 5, 1106-1120.

29 G. Gunawardena, G. Hills, I. Montenegro and B. Scharifker, J. Electroanal. Chem. Interfacial Electrochem., 1982, 138, 225239.

30 A. I. Bhatt, A. M. Bond and J. Zhang, J. Solid State Electrochem., 2006, 11, 1593-1603.

31 D. Pradhan and R. G. Reddy, Mater. Chem. Phys., 2014, 143, 564-569. 